Research Article

\title{
Investigation on Deicing Property of Steel Wool Fiber-Reinforced Asphalt Mixture by Induction Heating
}

\author{
Fa Yang, ${ }^{1}$ Kehong Li, ${ }^{2}$ Rui Xiong $\mathbb{D}^{2,3}$ Bowen Guan, ${ }^{2,3}$ and Hua Zhao ${ }^{4}{ }^{4}$ \\ ${ }^{1}$ Yunnan Communications Investment \& Construction Group Co. Ltd., Kunming 650228, China \\ ${ }^{2}$ School of Materials Science and Engineering, Chang'an University, Xi'an 710061, China \\ ${ }^{3}$ Engineering Research Center of Transportation Materials of Ministry of Education, Chang'an University, Xi'an 710061, China \\ ${ }^{4}$ School of Civil Engineering and Architecture, Nanchang University, Nanchang 330031, China \\ Correspondence should be addressed to Rui Xiong; xiongr61@126.com
}

Received 15 October 2019; Accepted 12 December 2019; Published 11 January 2020

Academic Editor: Candido Fabrizio Pirri

Copyright (c) $2020 \mathrm{Fa}$ Yang et al. This is an open access article distributed under the Creative Commons Attribution License, which permits unrestricted use, distribution, and reproduction in any medium, provided the original work is properly cited.

\begin{abstract}
In order to effectively solve the traffic safety problem caused by snow and ice covering the pavement in winter, steel wool fibers with different length and content were adopted in asphalt mixture to investigate its deicing performance. The deicing principle of steel wool fiber asphalt mixture by induction heating was expounded. Effects of different ice thicknesses, output currents, and ambient temperatures for asphalt mixture deicing performance were studied using an indoor-simulated induction heating deicing test. The deicing mechanism of steel wool fiber asphalt mixture by induction heating was analyzed. Grey relation entropy analysis between the average melting ice rate and the influencing factors was determined. The results show that the average ice melting rate of the asphalt mixture increases with the increase in steel wool fiber length and content. The steel wool fiber asphalt mixture heated by electromagnetic induction obtains satisfactory result. The average melting ice rate of asphalt mixture containing $6 \%$ steel wool fiber with a length of $3 \mathrm{~mm}$ can reach $0.50^{\circ} \mathrm{C} \cdot \mathrm{s}^{-1}$ at an ambient temperature of $-5^{\circ} \mathrm{C}$. The thinner the ice and the higher the ambient temperature, the higher the average melting ice rate. The output current is positively correlated with the average melting ice rate. The degree of influence of the five influence factors on the average melting ice rate is ranked in order as follows: fiber content, fiber length, output current, ambient temperature, and ice layer thickness.
\end{abstract}

\section{Introduction}

Traffic accidents caused by snow and ice covering on roads have long been a problem needing to be solved by domestic and foreign traffic maintenance departments. Due to the snow and ice covering on a road, the friction coefficient of the road is reduced and the vehicle braking function is insufficient and offset, which leads to frequent traffic accidents in winter [1-3]. It is reported that most traffic accidents in China are caused by snow and ice in winter, causing a large number of casualties and property losses. Therefore, it is urgent to study and test new road deicing technologies.

There are two main types of deicing methods commonly used on roads, "initiative mode" and "passive mode" deicing methods. Mechanical and chemical methods are "passive mode." These two methods are still the main methods of deicing or snow-melting in China [4]. Mechanical deicing is efficient, but the equipment maintenance cost is high, and the road surface structure and ancillary facilities may be damaged. China produces more than 30 million tons of chemical salts for road deicing every year. Although the effect is remarkable, the salts cause environmental pollution [5]. Furthermore, salt erosion will damage asphalt pavement and shorten its service life $[6,7]$. At present, "initiative mode" deicing methods commonly used at home and abroad mainly include the elastic paving method [8-10], the low-freezing point method $[11,12]$ and heat energy method [13]. Although these methods have good deicing effectiveness, there are still problems remaining, such as ice thickness and environmental temperature restrictions, construction costs, and energy consumption. In recent years, researchers have studied noncontact heating technologies such as microwave heating 
and induction heating, providing new ideas for road deicing. Gao et al. studied the deicing performance of steel wool fibermodified asphalt concrete under microwave heating, and they obtained the optimal content of different steel fiber types at ambient temperature of $-5^{\circ} \mathrm{C}$ and $-10^{\circ} \mathrm{C}$, respectively [14]. Microwave heating deicing energy consumption is low and can effectively reduce the bonding force between the road and the ice layer, but microwave radiation may bring microwave pollution. Sun et al. studied the deicing performance of asphalt mixture by microwave heating and induction heating, respectively, determining that the average deicing rate of induction heating could be increased from less than $1 \mathrm{~g} / \mathrm{min}$ to more than $10 \mathrm{~g} / \mathrm{min}$, and the deicing effect was significant [15]. Although electromagnetic induction heating technology has been introduced, there are few research studies on the heating temperature rise law of melting ice under induction heating and the influencing factors of deicing performance under induction heating.

In view of this, this paper adopts electromagnetic induction heating technology, taking steel wool fiber as the induction heating material. The effects of steel wool fiber with different length and content were used in asphalt mixture to study its deicing performance. The effects of different ice thicknesses, output currents, and ambient temperatures on asphalt mixture deicing performance were studied using the indoor-simulated induction heating deicing test. The grey relational entropy analysis method was adopted to determine the grey entropy correlation degree between the average melting ice rate and the influencing factors by taking the average melting ice rate VT as the evaluation index. The study results provide a new reference to improve the efficiency of asphalt pavement induction heating deicing in actual working conditions.

\section{Materials, Test Equipment, and Methods}

\subsection{Materials}

2.1.1. Asphalt. The SK-90\# matrix asphalt whose penetration is between $80 \sim 100(0.1 \mathrm{~mm})$ was used for all experiments. Table 1 shows the physical properties of asphalt binder following ASTM standards [16].

2.1.2. Aggregate and Limestone Mineral Filler. The coarse and fine aggregates were crushed basalt, with a density of $2.830 \mathrm{~g} / \mathrm{cm}^{3}$ and maximal size of $16 \mathrm{~mm}$. The crushing value and Los Angeles abrasion value (LAA) of coarse aggregate are $9.9 \%$ and $12.5 \%$, respectively, and the fine aggregate angularity (FAA) is $45 \%$.

Table 2 presents the gradation of mixed aggregate used in this paper, which is generally applied on asphalt pavement surfaces in western China. Mineral filler is levigated limestone with a density of $2.705 \mathrm{~g} / \mathrm{cm}^{3}$, whose particle size ranges from $0 \mathrm{~mm}$ to $0.3 \mathrm{~mm}$, with a passing range $(75 \mu \mathrm{m})$ of $95.1 \%$ by weight.

2.1.3. Steel Wool Fiber. Steel wool fiber was selected as the induction heating material. Its lengths were $1 \mathrm{~mm}, 3 \mathrm{~mm}$, or
$5 \mathrm{~mm}$, diameter was $70 \mathrm{um}$, density was $7.220 \mathrm{~g} / \mathrm{cm}^{3}$, and the tensile strength of a single wire was $800 \mathrm{MPa}$. Its macro- and micromorphologies are shown in Figures 1 and 2 .

2.2. Test Equipment. HD-5 KW automatic high-tuning induction heating equipment manufactured by Wuxi Hertz Induction Heating Equipment Co., Ltd. was used in the experiment. As shown in Figure 3, the equipment can quickly, efficiently, and accurately heat the test target. Researchers used the Ti450 infrared thermal imager produced by Fluke Company, USA. As shown in Figure 4, the measurement range is $-20^{\circ} \mathrm{C} \sim 800^{\circ} \mathrm{C}$. Within this range, the imager can clearly observe the changes of thermal imaging on the ice surface, and the thermometer can record the changes in ice surface temperature in real time.

\subsection{Methods}

2.3.1. Preparation of Steel Wool Fiber Asphalt Mixture. Steel wool fibers are easy to agglomerate due to static electricity, and they are easy to disperse unevenly when mixed with asphalt mixture. After different mixing process attempts, researchers determined that the optimal scheme to solve these problems is as follows: after the aggregate and the asphalt binder were mixed for $90 \mathrm{~s}$, each $10 \mathrm{~g}$ steel wool fiber was mixed for $30 \mathrm{~s}$, and the steel wool fiber was mixed for $90 \mathrm{~s}$ until the steel wool fiber was finally blended. Finally, the asphalt mixture test specimen was prepared. The temperature of asphalt mixture was about $155^{\circ} \mathrm{C}$ in the mixing process and $145^{\circ} \mathrm{C}$ in the compaction process.

2.3.2. Principle of Asphalt Mixture Deicing by Electromagnetic Induction Heating. The principle of electromagnetic induction heating is based on Faraday's law of electromagnetic induction and Joule's law; that is, electric energy is converted to magnetic energy, magnetic energy is converted to electric energy, and electric energy is ultimately converted to heat energy. The alternating current generated by the induction heating power source generates alternating magnetic fields through the coil. However, the asphalt mixture is not a conductive material. After adding a conductive material (steel wool fiber), the conductive material will continuously cut the alternating magnetic line, and the internal will generate circulating closed alternating currents. The steel wool fiber asphalt mixture will generate induced electromotive force in the alternating electromagnetic field, and the value is proportional to the magnetic field strength. The relationship between the two is

$$
\varepsilon=\omega \cdot B \cdot A=2 \pi \cdot f \cdot \mu \cdot H \cdot A,
$$

where $\varepsilon$ is the induced electromotive force $(V) ; \omega$ is the angular frequency of the magnetic field ( $\mathrm{rad} / \mathrm{s}) ; B$ is magnetic flux (Wb); $A$ is the area enclosed by the steel wool fiber loop $\left(\mathrm{m}^{2}\right) ; f$ is field frequency $(\mathrm{Hz}) ; \mu$ is the coefficient of magnetic flux; and $H$ is magnetic field strength $(T)$.

The alternating current causes the atoms inside the conductive material to move irregularly at high speeds. The heat 
TABLE 1: Technical properties of SK-90\# asphalt binder.

\begin{tabular}{|c|c|c|c|c|}
\hline Material & Test items & Unit & Value & Specification \\
\hline \multirow{6}{*}{ Matrix asphalt binder } & Penetration at $25^{\circ} \mathrm{C}$ & $0.1 \mathrm{~mm}$ & 86 & ASTM D5-97 \\
\hline & Ductility at $15^{\circ} \mathrm{C}$ & $\mathrm{Cm}$ & 182 & ASTM D113-99 \\
\hline & Softening point & ${ }^{\circ} \mathrm{C}$ & 47.0 & ASTM D36-06 \\
\hline & Wax content & $\%$ & 1.75 & ASTM D3344-90 \\
\hline & Flash point & ${ }^{\circ} \mathrm{C}$ & 304 & ASTM D92-02 \\
\hline & Specific gravity & Non & 1.030 & ASTM D70-76 \\
\hline \multirow{3}{*}{ RTFO binder* } & Mass loss & $\%$ & 0.15 & ASTM D2872-04 \\
\hline & Penetration ratio at $25^{\circ} \mathrm{C}$ & $\%$ & 60.5 & ASTM D5-97 \\
\hline & Ductility at $10^{\circ} \mathrm{C}$ & $\mathrm{cm}$ & 9.8 & ASTM D113-99 \\
\hline
\end{tabular}

* Rolling thin film oven (RTFO) aged, according to ASTM D2872-04.

TABle 2: Aggregate gradation for AC-13 mixture design.

\begin{tabular}{|c|c|c|c|c|c|c|c|c|c|c|}
\hline Sieve size $(\mathrm{mm})$ & 16 & 13.2 & 9.5 & 4.75 & 2.36 & 1.18 & 0.6 & 0.3 & 0.15 & 0.075 \\
\hline Percent passing (wt. \%) & 100 & 95.5 & 72.0 & 47.1 & 33.4 & 23.4 & 15.2 & 8.7 & 7.3 & 5.2 \\
\hline Required passing range (wt. \%) & 100 & $90-100$ & $68-85$ & $38-68$ & $24-50$ & $15-38$ & $10-28$ & $7-20$ & $5-15$ & $4-8$ \\
\hline
\end{tabular}

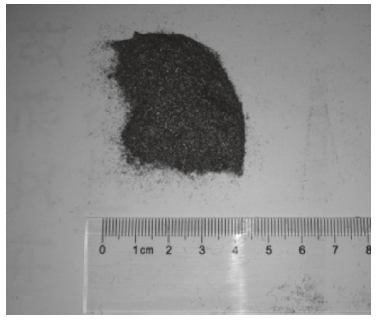

(a)

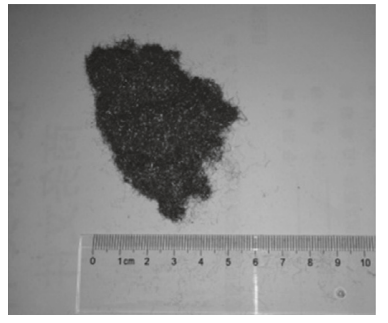

(b)

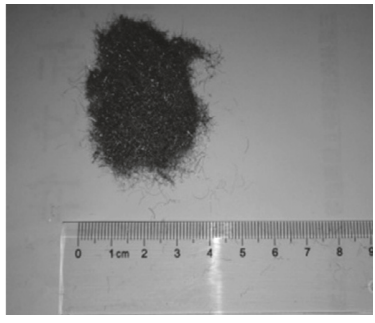

(c)

Figure 1: Morphology of steel wool fiber. (a) $1 \mathrm{~mm}$. (b) $3 \mathrm{~mm}$. (c) $5 \mathrm{~mm}$.

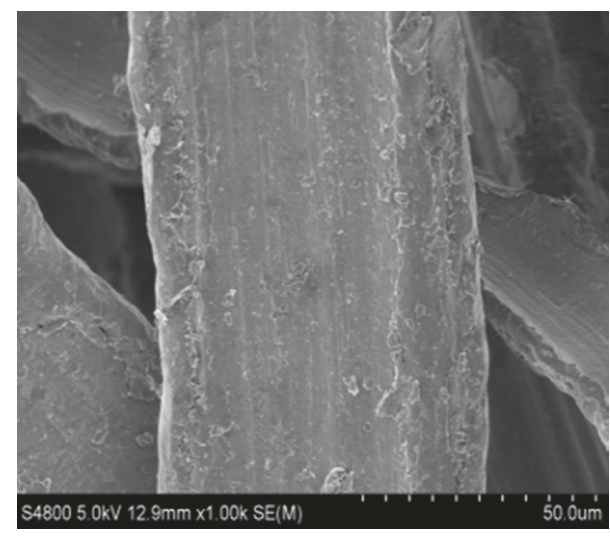

Figure 2: Micrographs of steel wool fiber.

energy generated by the friction and collision between the atoms can be expressed in the following equation of Joule's law.

$$
P=R \cdot I^{2} \cdot t=\left(\frac{\varepsilon}{R}\right)^{2} \cdot R \cdot t=\frac{4 \pi^{2} \cdot f^{2} \cdot H^{2} \cdot \mu^{2} \cdot A^{2}}{R} \cdot t
$$

where $P$ is heat generated per unit of time $(\mathrm{J}) ; R$ is conductive material resistance $(\Omega)$; $I$ is constant current (A); and $t$ is magnetic field time of contact (s).

Electromagnetic induction heating deicing involves heating the steel wool fibers in an asphalt mixture by

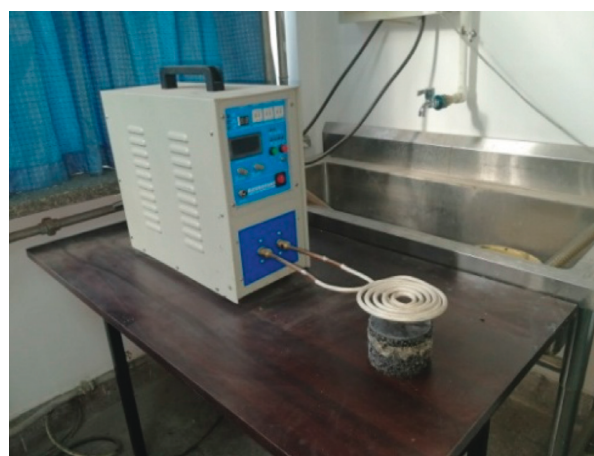

FIGURE 3: Electromagnetic induction heating equipment.

induction heating and then transmitting heat into asphalt binder and aggregating along with the ice in the asphalt mixture structure and finally to the ice surface. After induction heating, the thin ice layer on the surface of the asphalt mixture can directly melt into water, and the thick ice layer can further reduce the bonding force between the ice layer and the asphalt mixture surface through induction heating. Then, the ice layer can be easily removed with the help of machinery or human power. The electromagnetic induction heating deicing principle of the selected equipment is shown in Figure 5. 


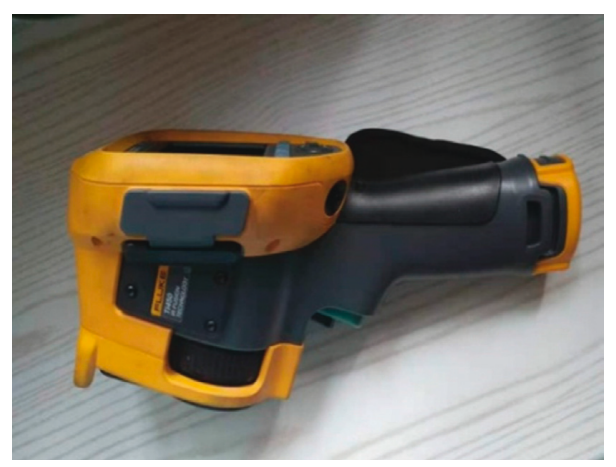

FIGURE 4: Infrared thermal imaging instrument.

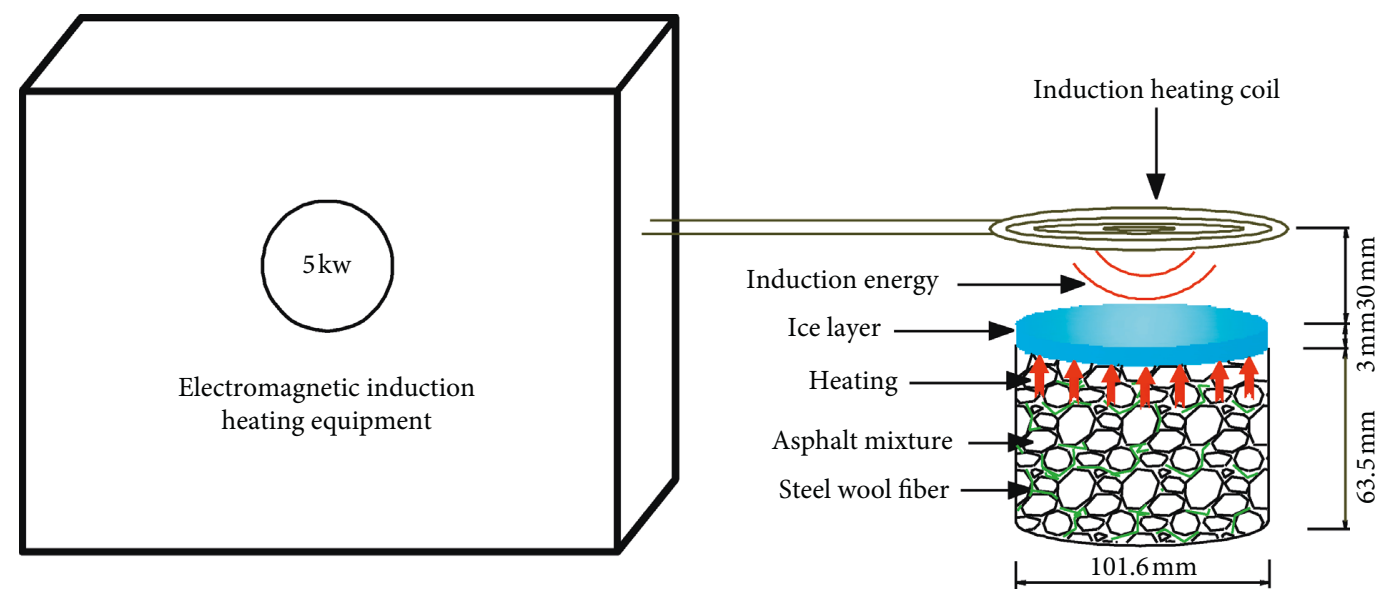

FIGURE 5: Sketch diagram of induction heating deicing of steel wool fiber asphalt mixture.

\subsubsection{Method of Deicing by Electromagnetic Induction} Heating. Standard Marshall specimens of steel wool fiber asphalt mixture with a length of $1 \mathrm{~mm}, 3 \mathrm{~mm}$, and $5 \mathrm{~mm}$ and content of $2 \%, 3 \%, 4 \%, 5 \%$, and $6 \%$ were prepared. After vacuum-pumping under the condition of retaining water, $3 \mathrm{~mm}-, 6 \mathrm{~mm}$-, and $9 \mathrm{~mm}$-high water layers were injected and then frozen for 16 hours in the constant temperature environments of $-5^{\circ} \mathrm{C},-10^{\circ} \mathrm{C}$, and $-15^{\circ} \mathrm{C}$. The output current of electromagnetic induction heating equipment was adjusted to be $330 \mathrm{~A}, 430 \mathrm{~A}, 530 \mathrm{~A}$, and $630 \mathrm{~A}$, respectively. The effect of steel wool fiber length and content, ice thickness, ambient temperature, and output current on asphalt mixture deicing performance was studied. The infrared thermal imager and the infrared thermometer were used to observe the change of the surface image and temperature of the specimen's ice layer, and the recording was performed every $15 \mathrm{~s}$. When the ice layer surface reached $0^{\circ} \mathrm{C}$, the total time of induction heating was recorded, and the variation law of temperature and average melting ice rate of the sample ice layer surface was analyzed. The sample test process is shown in Figure 6.

2.3.4. Grey Relation Entropy Analysis Method. The grey relation entropy analysis method is an important method in grey system theory and an effective method for poor information system analysis [17]. It can solve many shortcomings in general grey relational analysis, such as local point correlation tendency and partial information loss. This paper uses this method to study the significance of each influencing factor, which can make the analysis results more accurate. The calculation steps are as follows:

(i) Grey correlation coefficient: $X$ is the grey correlation factor set. $x_{0}\left(x_{0}(1), x_{0}(2), \ldots, x_{0}(n)\right)$ is the reference column, and $x_{i}\left(x_{i}(1), x_{i}(2), \ldots, x_{i}(n)\right)$ $(i=1,2, \ldots, m)$ is the comparison column. The grey correlation coefficient between the comparison column and the reference column can be determined as follows:

$$
\begin{aligned}
\xi_{i}[ & \left.x_{0}(k), x_{i}(k)\right] \\
& \cdot \frac{\min _{i=1, m} \min _{k=1, n} \Delta_{i}(k)+\rho \max _{i=1, m} \max _{k=1, n} \Delta_{i}(k)}{\Delta_{i}(k)+\rho \max _{i=1, m} \max _{k=1, n} \Delta_{i}(k)},
\end{aligned}
$$

where $\min _{i=1, m} \min _{k=1, n} \Delta_{i}(k)$ is the minimum difference between the two poles and $\max _{i=1, m}$ $\max _{k=1, n} \Delta_{i}(k)$ is the maximum difference between the two poles. $\rho$ is the resolution coefficient, which is generally 0.5 .

(ii) Grey relational entropy and grey entropy correlation degree: $X$ is a discrete sequence and $x_{i} \in x(i=$ $1,2, \ldots, m)$ is a comparison column. 


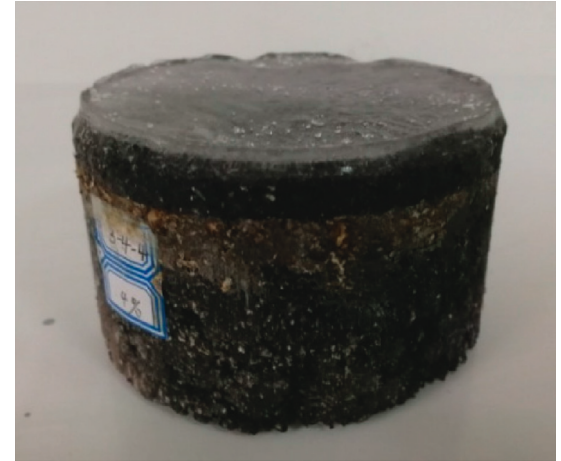

(a)

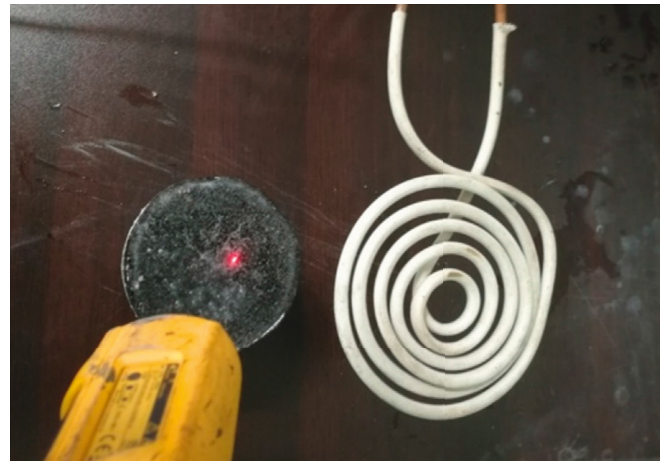

(b)

Figure 6: (a) Specimen before the test; (b) specimen during the process of test.

$P_{h} \triangleq \frac{\xi\left[x_{0}(h), x_{i}(h)\right]}{\sum_{k=1}^{n} \xi\left[x_{0}(h), x_{i}(h)\right]}, \quad P_{h} \in P_{i}(h=1,2, \ldots, n)$,

where $P_{h}$ is called the density value of the distribution. The grey relational entropy of $x_{i}$ is expressed as

$$
H\left(R_{i}\right) \triangleq-\sum_{k=1}^{n} P_{h} \ln P_{h}
$$

The grey entropy correlation of the sequence $x_{i}$ is expressed as

$$
E\left(x_{i}\right) \triangleq \frac{H\left(R_{i}\right)}{H_{\max }}
$$

where $E\left(x_{i}\right)$ represents the maximum value of the difference information column composed of $n$ elements.

(iii) Analysis of key influencing factors: according to the order of grey entropy correlation degree, the greater the entropy degree of the comparison column, the stronger the correlation between the comparison column and the reference column, thus determining the significance of the influencing factors and conducting targeted analysis.

\section{Results and Discussion}

3.1. Evaluation Index: Average Melting Ice Rate. $V_{T}$ is the average melting ice rate, and the indicator reflects the melting ice efficiency of the induction heating steel wool fiber asphalt mixture. The larger the value is, the stronger is the melting ice ability of the steel wool fiber asphalt mixture.

$$
V_{T}=\frac{\Delta T}{t}
$$

where $V_{T}$ is the average melting ice rate $\left({ }^{\circ} \mathrm{C} \cdot \mathrm{s}^{-1}\right) ; \Delta T$ is the difference value of ice layer surface temperature before and after induction heating $\left({ }^{\circ} \mathrm{C}\right)$; and $t$ is the induction heating time (s).
3.2. The Law of Ice Layer Surface Temperature of Specimen in Infrared Thermal Imaging. The temperature change of steel wool fiber with $3 \%$ content and $5 \mathrm{~mm}$ length during heating is recorded by the infrared thermal imager as an example. As shown in Figure 7, the infrared thermal imaging can clearly distinguish the ice layer surface temperature changes of the steel wool fiber asphalt mixture under induction heating conditions, and it can also be used as an effective means to judge the surface deicing rate of the sample.

3.3. The Effect of Different Factors on Melting Ice Rate by Induction Heating. In order to study the influence law of different influencing factors on the induction melting ice rate of asphalt mixture, researchers adopted the control variable method. The initial length and content of steel wool fiber were $3 \mathrm{~mm}$ and $4 \%$, respectively, the initial ice thickness was $3 \mathrm{~mm}$, the initial ambient temperature was $-15^{\circ} \mathrm{C}$, and the initial output current was $630 \mathrm{~A}$.

3.3.1. Effect of Ice Thickness on Melting Ice Rate under Different Steel Wool Fiber Length. The ice thickness of steel wool fiber Marshall specimens prepared is shown in Figure 8 , and the variation law of temperature and the average melting ice rate during induction heating are shown in Figures 9 and 10 .

It can be obtained from Figures 9 and 10, when the content and length of steel wool fiber within the asphalt mixture specimen remains the same, the slope of melting ice heating curve becomes smaller as the thickness of the ice layer increases. As the thickness of the ice layer increases, the ice melting time until the ice layer surface reaches $0^{\circ} \mathrm{C}$ becomes longer and the average melting ice rate decreases. With the same content and ice thickness, the average melting ice rate increases with the increase of fiber length. With the increase in ice thickness, the variation trend of average melting ice rate decreases as the fiber length increases. As the thickness of the ice layer increases, the heat generated in the asphalt mixture is transmitted to the ice surface, and the time required for the ice surface to reach $0^{\circ} \mathrm{C}$ increases, which reduces the average melting ice rate. 


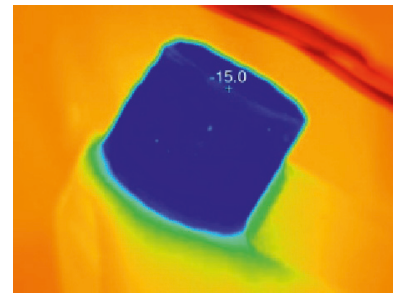

(a)

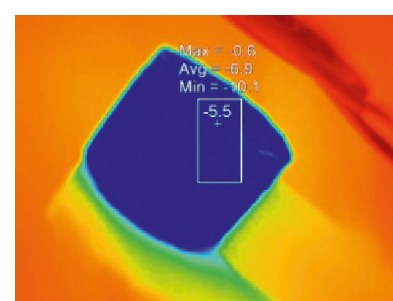

(b)

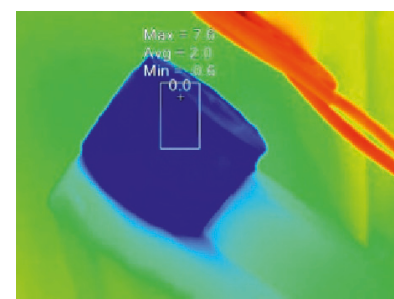

(c)

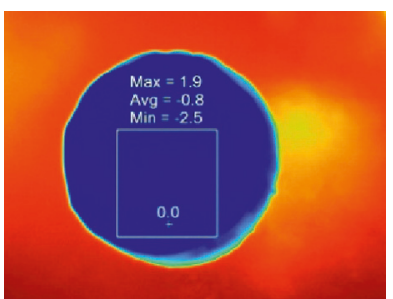

(d)

FIgURE 7: (a) Ice layer surface initial temperature; (b) temperature at $30 \mathrm{~s}$; (c) temperature at $54 \mathrm{~s}$; and (d) temperature distribution at $0^{\circ} \mathrm{C}$ on the surface of the ice layer.

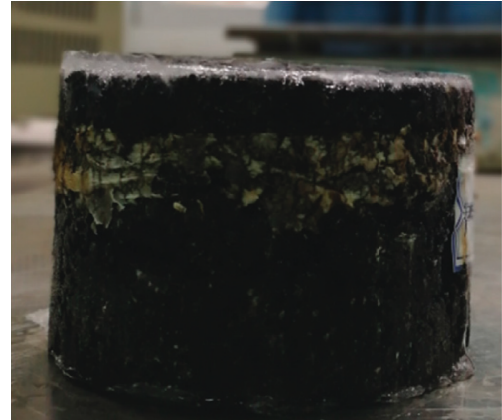

(a)

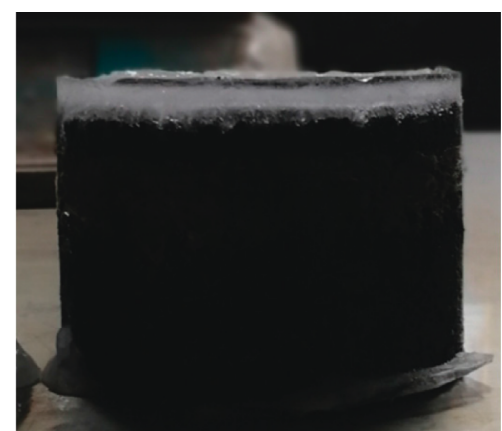

(b)

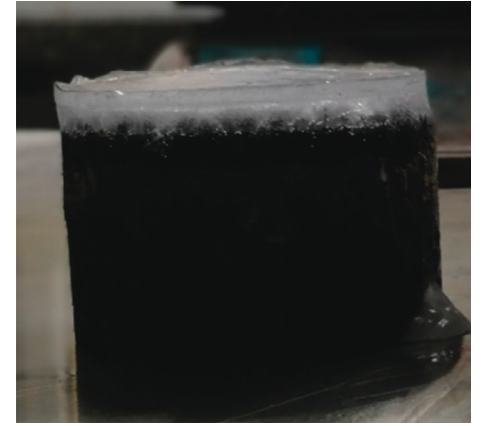

(c)

FIGURE 8: Marshall specimen with different ice thickness. (a) $3 \mathrm{~mm}$. (b) $6 \mathrm{~mm}$. (c) $9 \mathrm{~mm}$.

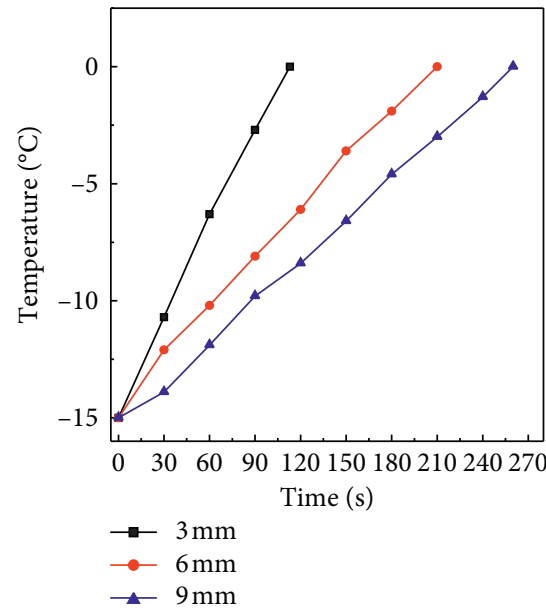

(a)

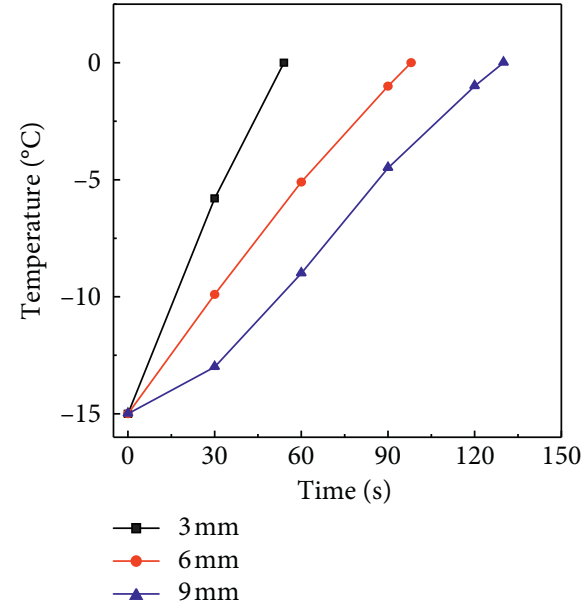

(b)

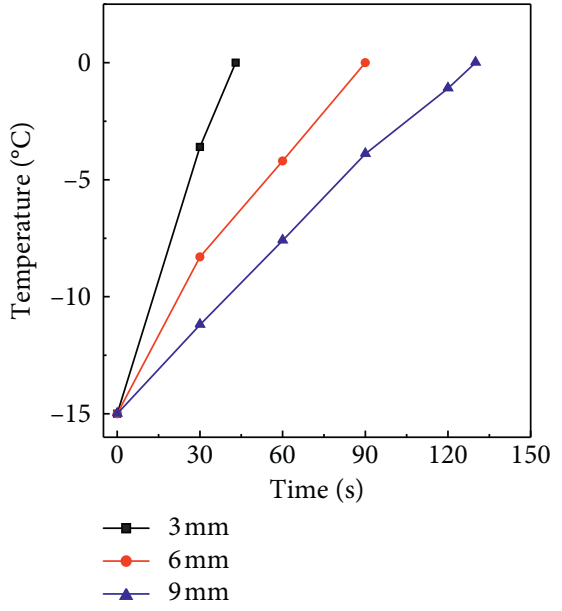

(c)

FIgURE 9: Effects of ice thickness on melting ice temperature under different steel wool fiber lengths. (a) $1 \mathrm{~mm}$; (b) $3 \mathrm{~mm}$; (c) $5 \mathrm{~mm}$.

3.3.2. Effect of Ambient Temperature on Melting Ice Rate of Steel Wool Fibers with Different Lengths. The effect of ambient temperature on the melting ice temperature and the average melting ice rate of steel wool fibers under different lengths are shown in Figures 11 and 12.

As shown in Figures 11 and 12, under the same length of steel wool fiber, the ambient temperature increases, the temperature rise trend of melting ice increases through induction heating, the total time for the ice layer surface to reach $0^{\circ} \mathrm{C}$ decreases, and the average melting ice rate presents an increasing trend. Low ambient temperatures will lead to more heat loss in asphalt mixture and less heat conduction to the surface of the ice layer; additionally, the ice layer maintains $0^{\circ} \mathrm{C}$ for a longer time, and the average melting ice rate decreases. At the same ambient temperature, the average melting ice rate increases with the increase of fiber length, indicating that the heat generated by induction heating of longer fibers is more than that of shorter fibers.

3.3.3. Effect of Output Current on Melting Ice Rate under Different Steel Wool Fiber Contents. Variation laws for melting ice temperature and average melting ice rate under 


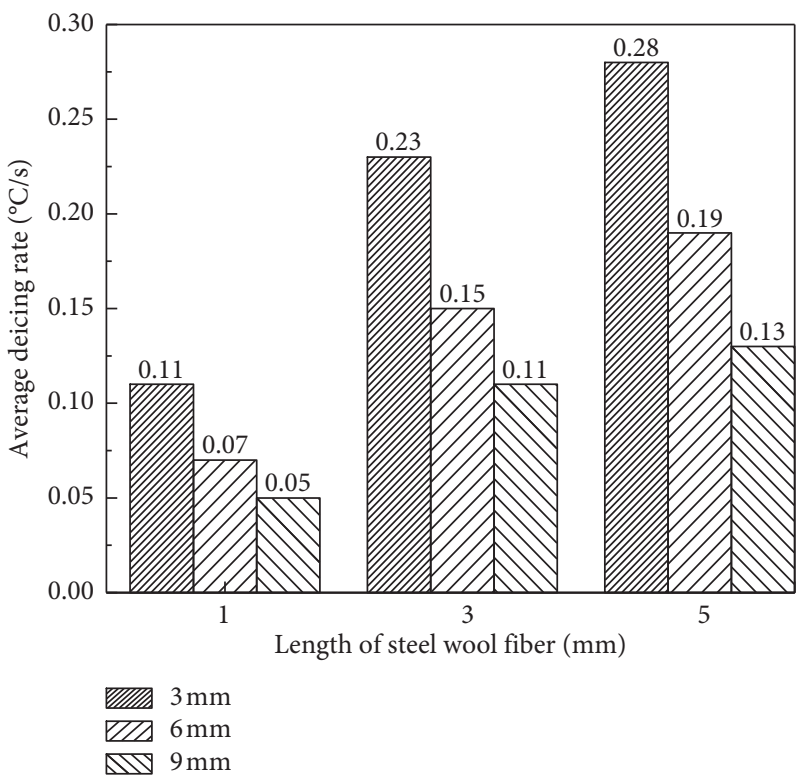

FIGURE 10: Effect of ice thickness on average melting ice rate under different steel wool fiber lengths.

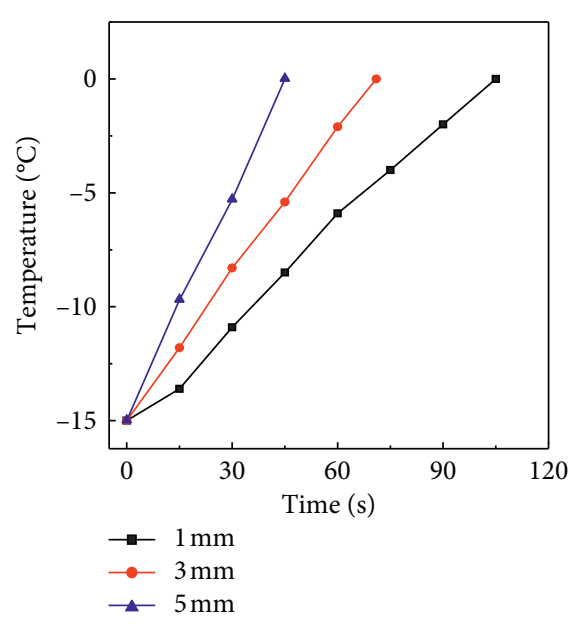

(a)

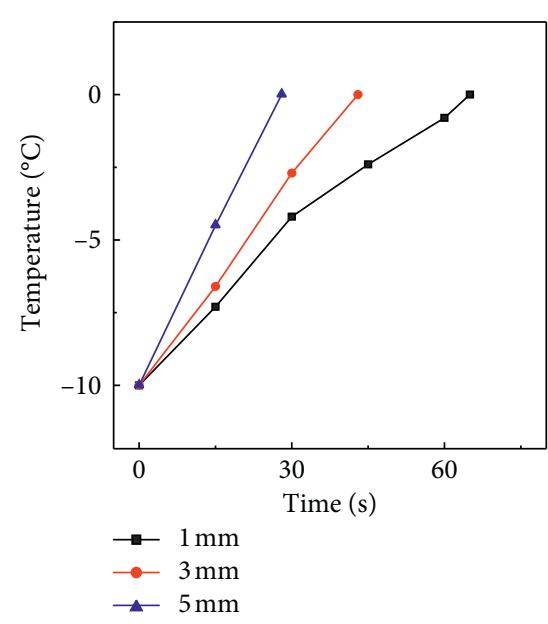

(b)

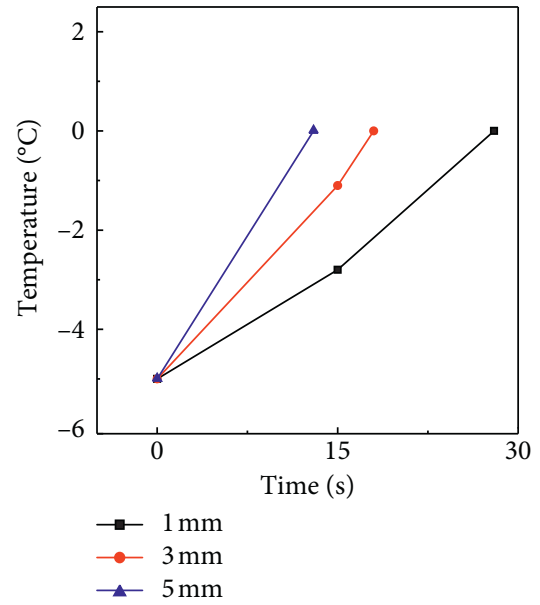

(c)

FIGURE 11: Effects of ambient temperature on melting ice temperature under different steel wool fiber lengths. (a) $-15^{\circ} \mathrm{C}$; (b) $-10^{\circ} \mathrm{C}$; and $(\mathrm{c})$ $-5^{\circ} \mathrm{C}$.

induction heating with output current of steel wool fiber of the same length and different content are shown in Figures 13 and 14 .

According to Figures 13 and 14, under the same content of steel wool fibers, the output current increases, which gradually increases the slope of the heating curve of melting ice under induction heating, shortens the total time for the ice layer surface to reach $0^{\circ} \mathrm{C}$, increases the average melting ice rate, and enhances the melting ice performance. Due to the increase in output current, the magnetic field will be strengthened, and the current generated by the magnetic field of steel wool fiber cutting will be increased. Therefore, the increase of heat generation enhances the melting ice performance of asphalt mixture.
3.4. Mechanism of Asphalt Mixture Deicing by Electromagnetic Induction Heating. According to the abovementioned statements, equation (1) of Faraday's law of electromagnetic induction, and equation (2) of Joule's Law, the induced electromotive force depends on the variation of magnetic field intensity and flux. When conditions are controlled for other factors to remain unchanged, the output current increases; that is, the increase of the magnetic field strength causes the alternating current generated in the conductor to become larger, the heat generated by the conductor increases, and the average melting ice rate increases.

Maintaining a constant current for induction heating equipment will produce constant magnetic field and constant electromotive force. Keeping other factors constant, the Joule heat generated by induction heating is inversely proportional 


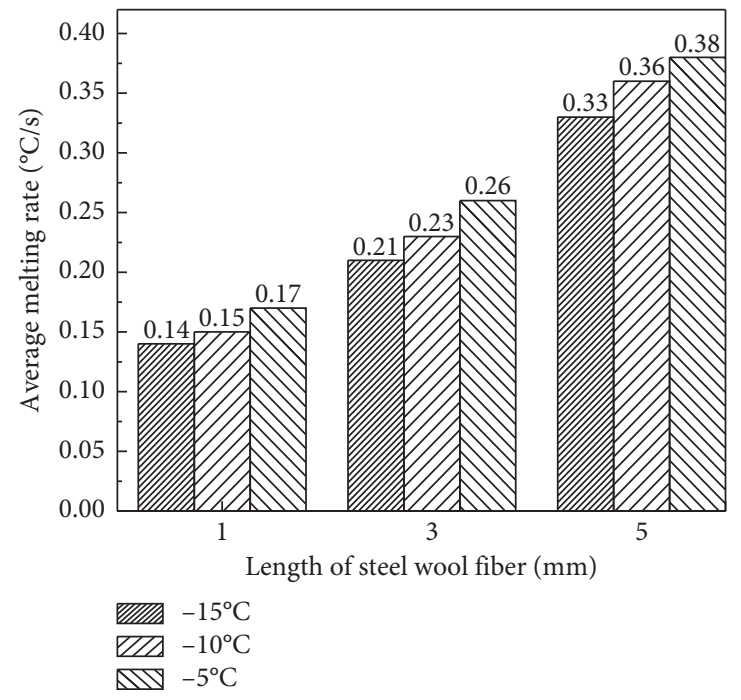

FIgURE 12: Effect of ambient temperature on average melting ice rate under different steel wool fiber lengths.

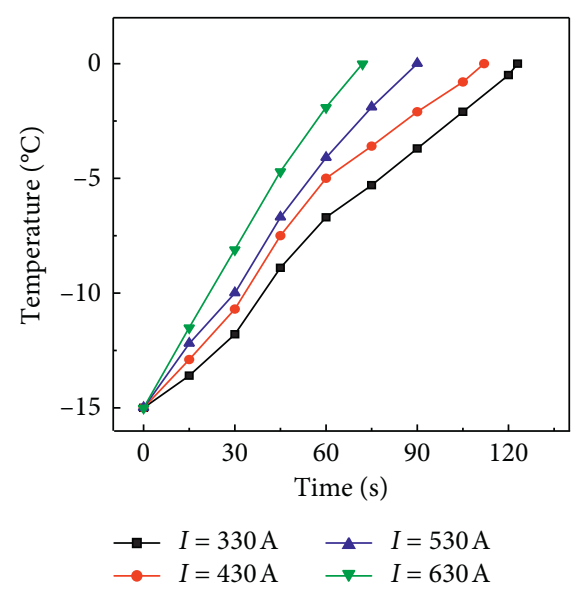

(a)

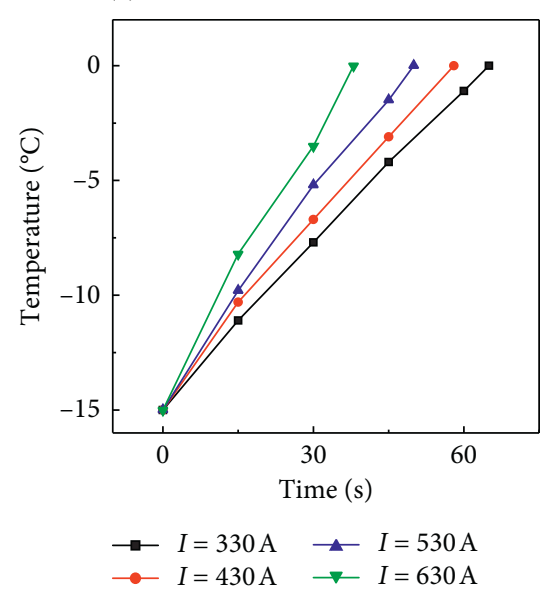

(d)

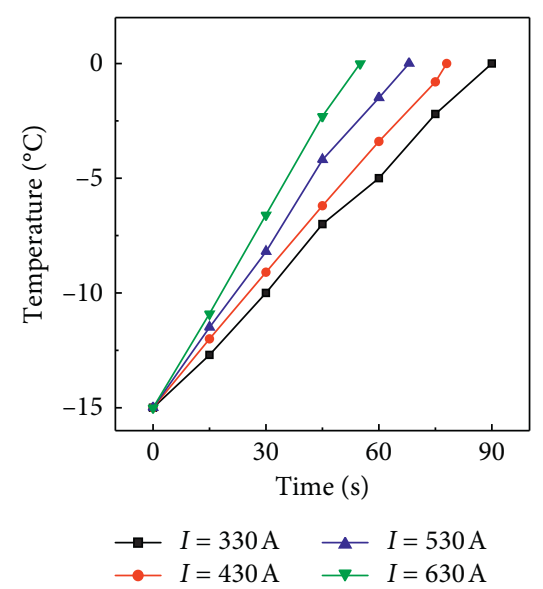

(b)

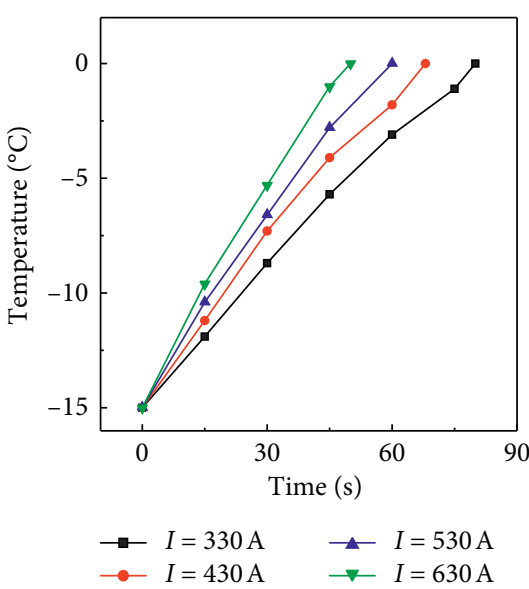

(c)

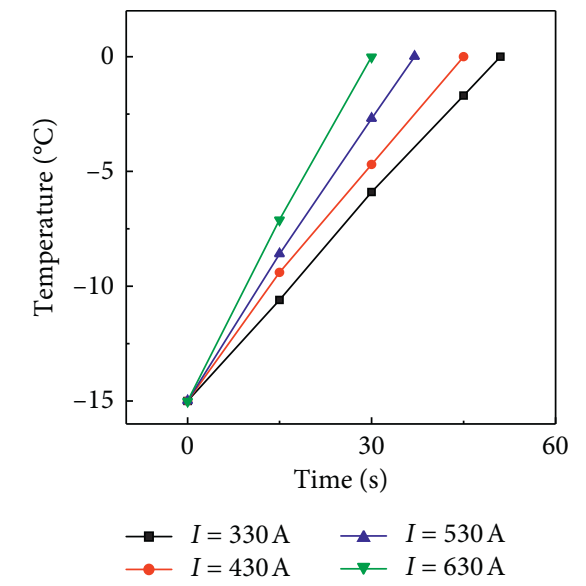

(e)

FIGURE 13: Effects of output current on melting ice temperature under different steel wool fiber contents. (a) 2\%; (b) $3 \%$; (c) $4 \%$; (d) $5 \%$; and (e) $6 \%$.

to the resistance of the specimen. The smaller the resistance of the specimen is, the faster the heating rate is. Adding steel wool fiber can change the resistance of the specimen. When the length of steel wool fiber remains unchanged and the content increases, the resistance of the specimen will be reduced, the heating rate will be accelerated, and the melting ice 


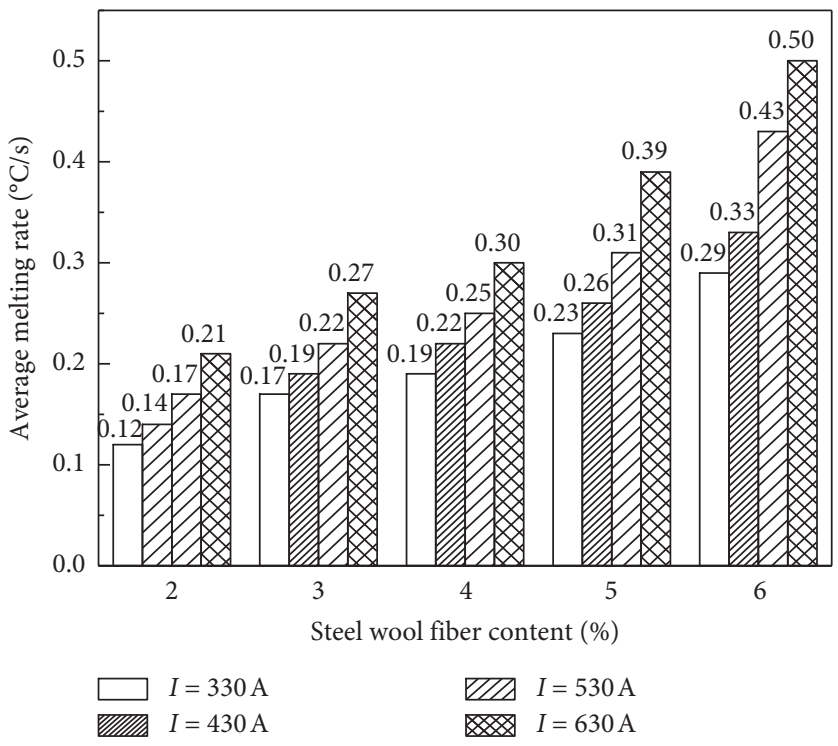

FIGURE 14: Effect of output current on average melting ice rate under different steel wool fiber contents.

TABLE 3: Grey entropy correlation of five influencing factors.

\begin{tabular}{lccccc}
\hline Influencing factors & Content of steel wool fiber & Length of steel wool fiber & Ice thickness & Output current & Ambient temperature \\
\hline Grey entropy correlation & 0.9812 & 0.9805 & 0.9725 & 0.9793 & 0.9767 \\
\hline
\end{tabular}

process will be accelerated. When the steel wool fiber content remains the same and the length increases under the same condition of mass, the longer fibers are easier to overlap and intertwine with each other inside the specimen, reducing the resistance of the specimen, generating larger closed alternating currents, releasing more heat, and accelerating the ice layer surface temperature of the specimen.

3.5. Grey Relation Entropy Analysis Result. According to the abovementioned test results, the length and content of steel wool fiber, ice thickness, ambient temperature, and output current all have certain effects on the average melting ice rate of asphalt mixture under induction heating. In order to determine the influence degree of these five factors on the average melting rate, the grey correlation entropy analysis method was adopted, and the calculation results are shown in Table 3.

It can be seen from Table 3 that the content of steel wool fiber has the largest influence on the average melting ice rate of induction heating, followed by the length of fiber, indicating that the type, content, and length of induction heating materials (internal factors) are the main factors affecting the road deicing. The next are the output current, ambient temperature, and ice thickness (external cause). The minimum correlation is the ice thickness, indicating that the ice thickness has little effect on the performance of melt ice by induction heating.

\section{Conclusions}

Steel wool fibers of different length and content were adopted in asphalt mixture to investigate its deicing performance. Different ice thicknesses, output currents, and ambient temperatures for asphalt mixture deicing performance were investigated by the indoor simulated induction heating deicing test in this study. Findings may be summarized as follows:

(i) The introduction of electromagnetic induction heating technology provides a new idea for road deicing. Electromagnetic induction heating technology has many advantages such as low energy consumption, no pollution, noncontact heating, and fast heating rate. The average deicing rate of the asphalt mixture increases with the increase in steel wool fiber length and content.

(ii) The average melting ice rate of asphalt mixture containing $6 \%$ steel wool fiber with a length of $3 \mathrm{~mm}$ can reach $0.50^{\circ} \mathrm{C} \cdot \mathrm{s}^{-1}$ at an ambient temperature of $-5^{\circ} \mathrm{C}$, showing satisfactory deicing effect by induction heating.

(iii) According to the grey relational entropy analysis, five factors have an effect on the average melting ice rate of the asphalt mixture by induction heating. The steel wool fiber content and length (internal factor) are the main factors affecting deicing property of the asphalt mixture by induction heating.

(iv) Future research must examine how to further optimize the parameters, propose a reasonable prediction model, design the electromagnetic induction heating method that for deicing vehicles in different climatic conditions and actual working conditions, and improve the deicing efficiency of the road surface. 


\section{Data Availability}

The authors would like to declare that all the data in the manuscript were obtained by experiment and the data are true and effective in the manuscript.

\section{Conflicts of Interest}

The authors declare that they have no conflicts of interest.

\section{Authors' Contributions}

Fa Yang and Hua Zhao conducted investigation; Bowen Guan was responsible for the methodology; Rui Xiong was involved in project administration; Kehong Li wrote the original draft; and Rui Xiong was involved in review and editing of the maniscipt.

\section{Acknowledgments}

This work was financially supported by the National Natural Science Foundation of China (no. 51608046); the Traffic Innovation Management Consulting Research Project of Yunnan Province (no. 2019304); the Key Research and Development Project of Science and Technology Department of Jiangxi Province (no. 20192BBG70064), and the Fundamental Research Funds for the Central Universities, CHD (nos. 300102319202 and 300102319102 ).

\section{References}

[1] C. P. Shen, J. L. Lv, G. Q. Ma et al., "Research on maintenance technology of snow and ice removal on expressway in winter," Highway Traffic Technology, vol. 25, no. 4, pp. 239-242, 2008.

[2] H. Wang and Z. Wang, "Evaluation of pavement surface friction subject to various pavement preservation treatments," Construction and Building Materials, vol. 48, pp. 194-202, 2013.

[3] G. Z. Cheng, H. Li, and L. Xu, "Analysis of characteristics of snow covered pavement and its evaluation of driver's driving tension," Journal of Jilin University (Engineering Edition), vol. 41, no. 2, pp. 355-359, 2011.

[4] J. Wahlin, S. Leisinger, and P. A. Klein, "The effect of sodium chloride solution on the hardness of compacted snow," Cold Regions Science and Technology, vol. 102, pp. 1-7, 2014.

[5] H. Wang, J. Zhao, and Z. Chen, "Experimental investigation of ice and snow melting process on pavement utilizing geothermal tail water," Energy Conversion and Management, vol. 49, no. 6, pp. 1538-1546, 2008.

[6] K. Qin, Q. Y. Ma, and J. R. Wu, "Experimental study on properties of asphalt concrete under the coupling of temperature and corrosion," Silicate Bulletin, vol. 32, no. 5, pp. 952-956, 2013.

[7] T. Wang, D. D. Guo, Y. Chen et al., "Study on the effect of snow melting agent on the anti-sliding performance of road under low temperature conditions," Highway, vol. 64, no. 5, pp. 267-271, 2019.

[8] C. X. Zhou and Y. Q. Tan, "Influence factors of snow and ice removal performance of rubber granular asphalt mixture," Journal of Building Materials, vol. 12, no. 6, pp. 672-675, 2009.

[9] Y. Z. Chen and Z. X. Li, "Deicing mechanism of asphalt pavement with rubber particles," Journal of Central South
University (Natural Science Edition), vol. 44, no. 5, pp. 2073-2081, 2013.

[10] H. Wei, Q. He, Y. Jiao, J. Chen, and M. Hu, "Evaluation of anti-icing performance for crumb rubber and diatomite compound modified asphalt mixture," Construction and Building Materials, vol. 107, no. 15, pp. 109-116, 2016.

[11] W. S. Yu, X. C. Zhang, and K. Zhong, "Deicing characteristics of high elastic storage salt melting ice and snow asphalt mixture," Journal of China University of Mining and Technology, vol. 44, no. 5, pp. 912-916, 2015.

[12] Y. Q. Tan, Z. R. Sun, M. Guo et al., "Study on snow and ice removal performance of salt storage asphalt mixture," China Highway Journal, vol. 26, no. 1, pp. 23-29, 2013.

[13] W. J. Hu, Y. Q. Jiang, Z. L. Ma et al., "Research and analysis of bridge surface thermal snow melting model," Journal of Harbin Institute of Technology, vol. 39, no. 12, pp. 1895-1899, 2007.

[14] J. Gao, H. Guo, X. Wang et al., "Microwave deicing for asphalt mixture containing steel wool fibers," Journal of Cleaner Production, vol. 206, no. 1, pp. 1110-1122, 2019.

[15] Y. Sun, S. Wu, Q. Liu, J. Hu, Y. Yuan, and Q. Ye, "Snow and ice melting properties of self-healing asphalt mixtures with induction heating and microwave heating," Applied Thermal Engineering, vol. 129, pp. 871-883, 2018.

[16] R. Xiong, C. Chu, N. Qiao et al., "Performance evaluation of asphalt mixture exposed to dynamic water and chlorine salt erosion," Construction and Building Materials, vol. 201, pp. 121-126, 2019.

[17] Q. S. Zhang, Y. J. Guo, J. L. Deng et al., "Grey relational entropy analysis method," Systems Engineering Theory and Practice, vol. 16, no. 8, pp. 8-12, 1996. 


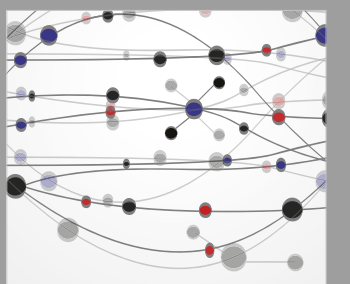

The Scientific World Journal
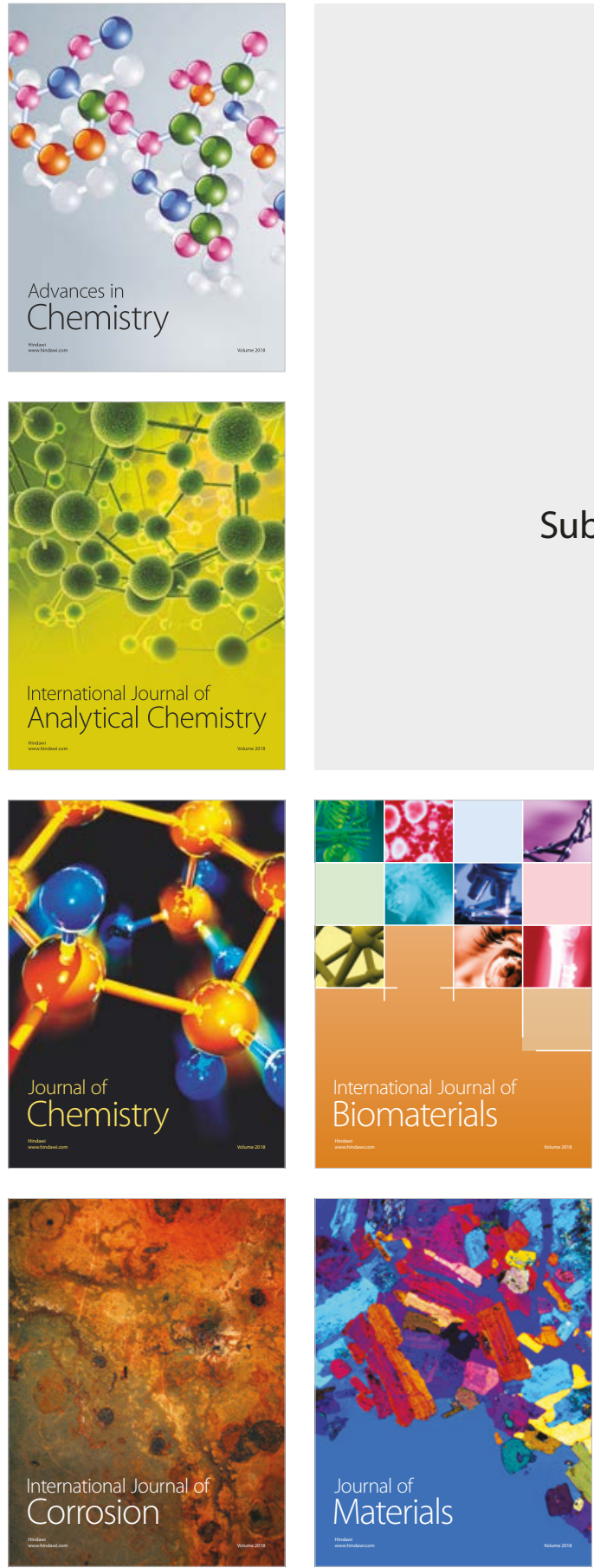

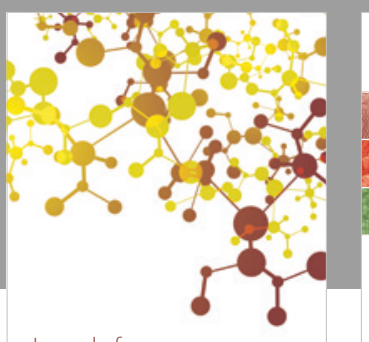

Journal of

Applied Chemistry
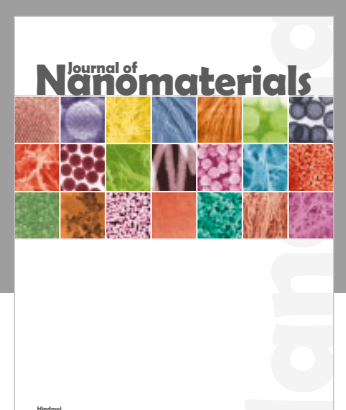

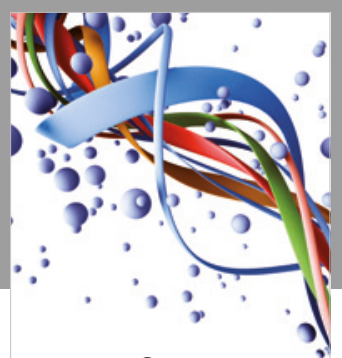

Scientifica

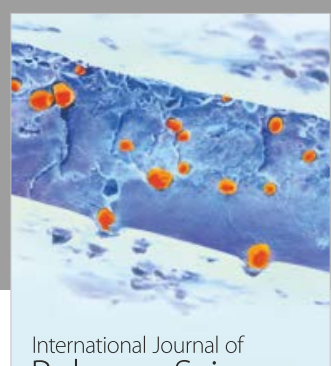

Polymer Science

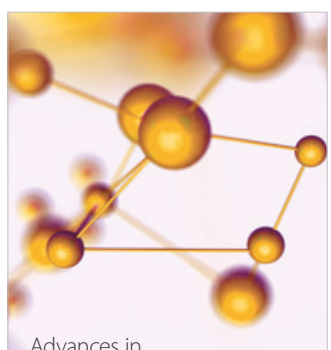

Physical Chemistry
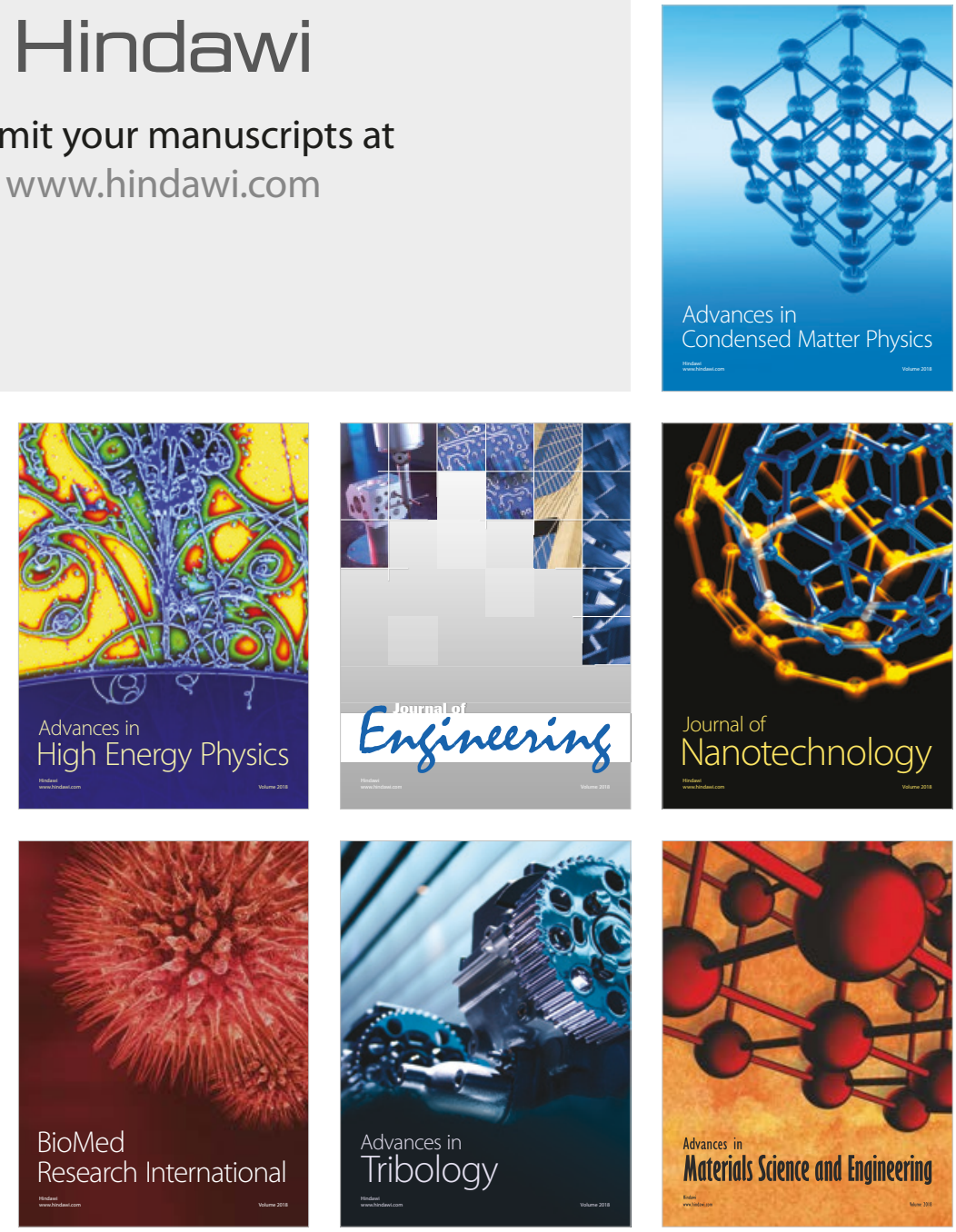